basis for schooling demand estimates instead of passive population and industrial forecasts. One must remember, however, that in addition to educational policy measures similarly directed placement and investment decisions made by enterprises and the measures of other national, regional and local administrative sectors are needed, so that the proposed effects would be realized.

The effects on population gained through educational policy are probably most clearly regional in effect. Educational policy also has effects extending to general population development, which appear indirectly, however. When educational opportunities improve an increasing number of young people of marriageable and childbearing age will participate in education, which may lower the birthrate if sufficient study and child care support is lacking. Growth in the proportion of students seems most likely in the near future, for in the legislation under reform concerning intermediate-level education the goal has been set to offer the opportunity to enter vocational training or general secondary education to every young person graduating from comprehensive school. The degree of participation in the labor market of trained women is higher than among the untrained, which may induce a lower birthrate.

Educational measures that can be seen as indirectly increasing the birthrate are compensation of expenses accrued by the schooling of children, of which perhaps the most significant measure implemented in the past few years is the realization by the end of this year of comprehensive education free-of charge to pupils. ${ }^{1}$ An attempt at increasing the equalization of costs through funds paid by society has occurred also in secondary- and college-level education. Currently under preparation is the proposition of arranging schooling for 6-year-olds. This reform can also be assumed to have possible favorable effects on the development of the birthrate.

\title{
Regional Policy and Population Development
}

\section{By OLAVI ÄNKÖ}

Office of the Council of State

The lack of balance in the regional population development of Finland increased markedly during the $1960 \mathrm{~s}$. This was caused mainly by swift and uncontrolled change in the industrial structure. Jobs in primary production diminished rapidly as a result of mechanization and other rationalization. Measures to further industrial production especially favored capital-intense production and thus also the intense concentration of production in the large centers of

1 The free-of-charge compulsory comprehensive school gradually introduced in this country consists of a six-year lower stage and a three-year higher stage. 
southern Finland. In addition the pull of Swedish labor markets increased considerably at the end of the decade. At the same time the so-called large age groups entered the labor markets and this further increased pressure to migrate. These factors together with regional differences in economy trends caused very strongly accelerated internal migration and emigration at the end of the decade. It ended in a situation where the population in all provinces except those of southern Finland actually started an absolute decline and emigration increased greatly.

The results of rapid migration showed up quickly in the sparsely populated areas. The decreasing population and the skewing of the age structure threatened basic services and the continued existence of whole village communities. On the other hand the areas of arrival began having congestion problems with fast-growing investment needs.

In the 1970 s population development has again become more balanced. The birthrate increased and for several years the flow of emigration changed into positive return migration, although lately emigration has again increased in a threatening way. Similarly internal migration has also begun to stabilize. The absolute decrease of the population has stopped in the developing areas on the whole, although it has continued in many rural areas.

\section{Regional policy measures}

Already in the middle of the 1960 s the increasing »escape from the rural areas to the urban areas» was considered such a non-desirable trend by social scientists that supportive action related to the policy for developing regions was taken in order to stimulate the economy of the so-called developing regions of eastern and northern Finland and in a lesser degree of central Finland. This action, however, consisted of rather cautious interest and tax rate reductions. That was not enough to compensate for the factors that favored centralized production. This action was intensified when the laws were renewed for the years $1970-75$. During these years new measures were also adopted and a special state fund was established to manage the financing of new production in the developing regions. When the current regional policy laws for the years 1975-79 were passed the structure of the supporting measures were again renewed into clearcut subventions and at the same time these measures were intensified. The fundamental feature of this legislation is to widen regional policy to include the whole country and all the social development policy sectors that are essential for the regional development of society.

The main features of regional policy measures now being applied in Finland are as follows:

- In order to apply regional policy measures, two zones have been established: a strongly supported development zone I and a moderately supported development zone II. In addition the most problematic communities of zone 
I and the archipelago can be designated as additional-support areas, and on the other hand problem communities outside the developing regions can be decreed areas where certain supportive measures can be applied.

- Aid can be granted for investments that either create new jobs or boost the production of processing or tourist industries. Investment aid covers part of the capital expenditure investments, aid for starting new operations covers part of the wage expenses for the first 2 or 3 years and training aid covers part of the cost of special training for the workers. Certain upper and lower limits have been placed on this aid depending on the zone, and within these limits the size of the aid will be determined on the basis of developmental needs and other investment factors of the locality in question. This aid is granted by the Ministry of Commerce and Industry. The Regional Development Fund Ltd. also shares in the financing. This Fund grants loans for investments either with or without warranties and also supports marketing etc. to some extent. In addition the Government Investment Fund, which finances large enterprises in the whole country, takes regional aspects into account when making its decisions. Certain minor tax policy measures are also applied to investments. In order to place investments in the best way from a regional policy standpoint, the government and the commercial and industrial organizations have agreed on special information and negotiation procedure.

- To help industry already in operation there is a transport aid for developing regions. Aid is granted for the transport of products processed in these regions according to a graduated scale based on the length and method of transportation. On the basis of labor and market conditions the Ministry of Labor may in special cases grant support to enterprises in order to maintain jobs during a recession.

- A regional gradation of price supports, among others, is used in agriculture. During the past year a graduated scale has also been introduced for interest and repayment terms on loans used to improve farms, depending on which development zone they are situated in.

\section{Regional policy planning}

The intension of regional policy based on the law to improve regional development is to guarantee the population of each region opportunities for a steady job, an increasing level of income and the availability of basic services. In order to set these goals in concrete terms and to operationalize them so that they fit in with the activity of different authorities, special regional developmant plans are being compiled. Regional development plans for provinces, made by authorities at the intermediate administrative level, have at present been sent to the municipalities and ministries for their official opinion. On the basis of these plans, the ministries, on their part, will draw up their own regional development plans for regional policy programs in their own administrative field. This 
work is closely connected to the rest of the economic planning and planning of action done in the ministries. The development plans are carried out, in part, directly by the municipality, the intermediate administration authorities and the ministries. The plans will also be used in part as a basis for regional policy legislation the next time these laws are renewed.

The regional development plans for provinces, drawn up by intermediate administration authorities, are being technically co-ordinated by directions given by the Office of the Council of State. The co-ordination of these plans in respect to scale and other particulars is fundamentally based on the use of special job and population forecasts drawn up for each province.

The criticism that arose as a result of the unbalanced population development in the 1960 s was directed, among others, at the population forecasts used by the authorities. Since the authorities used trend forecasts based on previous development as a guage on which to base their future activity, it was felt that by doing so they helped direct future developments in a way that intensified regional unbalance even further. Also, the trends used by the various authorities differed greatly from one another. For this reason the Office of the Council of State commissioned special job and population planning figure. These planning figures are based on reports on the development of production and demographic calculations on population development. Aside from these, consideration has also been given to the demands and goals presented by different authorities concerning their own activity sectors and to general social development policy goals. The most essential goal concerning the population development trend is that the province population rates do not decrease from the 1975 level The Council of State has recommended on October 13th, 1976 that the present planning figures be used as a guide by the authorities in planning measures which will affect regional development. The regional figures used by the Council of State have been further specified for each community by regional physical planning associations and provincial boards. In connection with the regional development plans the authorities in the intermediate administrative level have further worked out needed measures to realize the planning figures and have made proposals to check planning figures where necessary.

For the use of authorities, population planning figures have been calculated for each community by age and sex. These forecasts are used, for instance, in determining community building quotas for government loans, in planning the required number of school admissions for school authorities and in planning traffic maintenance.

The year 1975 is being used as a basis for job and population planning figures. Goal years for the planning figures are 1980 and 1985. Up to now the development on the part of population planning figures has on the whole corresponded to provincial planning figures. The rather intense stabilization of migration presumed by the planning figures has been partly caused by improved regional policy measures, and partly by the recession. In contrast to corresponding trend situations in the past, unemployment during the present strong recession has 
been noticeable not only in the developing regions but also in the centers of southern Finland and in the more important target areas of emigration. This most likely indicates that from the standpoint of future population development the regional timing of economic recovery is a central factor. An evaluation of job planning figures cannot be drawn up until later. At present there are no statistics available for this purpose.

Regional policy planning is being developed in such a way that consideration from a regional viewpoint would automatically be included in the planning procedures and decisions of the authorities. The realization of regional policy goals solely on the basis of a few special regional policy measures is not possible, at least not in a country like Finland where differences between and within regions are considerable. 